Portland State University

PDXScholar

6-25-1993

\title{
Correlations Between the School Situations Questionnaire-Revised and Speech and Language Disorders
}

Geraldine Teresa Comerford

Portland State University

Follow this and additional works at: https://pdxscholar.library.pdx.edu/open_access_etds

Part of the Speech and Rhetorical Studies Commons

Let us know how access to this document benefits you.

Recommended Citation

Comerford, Geraldine Teresa, "Correlations Between the School Situations Questionnaire-Revised and Speech and Language Disorders" (1993). Dissertations and Theses. Paper 4577.

https://doi.org/10.15760/etd.6461

This Thesis is brought to you for free and open access. It has been accepted for inclusion in Dissertations and Theses by an authorized administrator of PDXScholar. Please contact us if we can make this document more accessible: pdxscholar@pdx.edu. 
AN ABSTRACT OF THE THESIS OF Geraldine Teresa Comerford for the Master of Science in Speech Communication: Speech and Hearing Science presented June 25, 1993.

Title: Correlations Between the School Situations Questionnaire-Revised and Speech and Language Disorders.

APPROVED BY THE MEMBERS OF THE THESIS COMMITTEE:
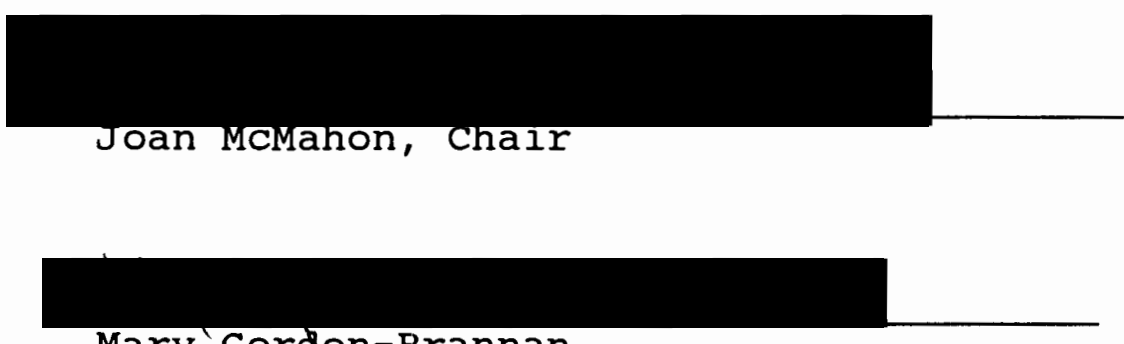
Mary Gordon-Brannan

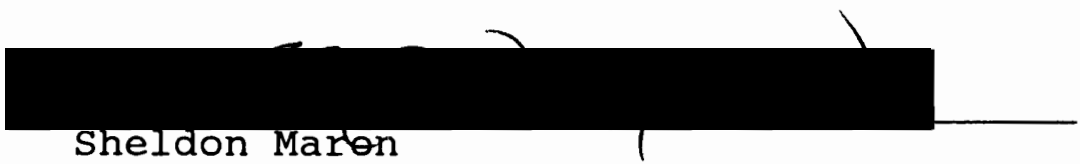

Many children with emotional and/or behavioral disorders also present with speech and language disorders (Baker \& Cantwell, 1982; Prizant et al., 1990). Children with attention deficits, in particular, have shown a much higher incidence of speech and language disorders than does the general population (Camarata et al., 1988 ; Cantwell \& Baker, 1987).

Traditionally, school speech-language pathologists have 
been responsible for conducting mass screenings to determine which children should be further evaluated for speech and language disorders. An increasing number of school districts are relying on teacher referrals to determine which children require speech-language evaluations. It was hypothesized that if teachers were able to identify children with attention deficits, these children may be appropriate for referral to speech-language pathologists for speech and language evaluation.

The purpose of this study was to determine the effectiveness of the School Situations Questionnaire-Revised (SSQ-R) (Barkley, 1991) in identifying children in the second grade, aged 7:0 to 8:11, who are speech and/or language disordered. This study sought to answer the following primary question: is there an association between the diagnosis of speech and/or language disorders (SLD), and detection by the $S S Q-R$ as at risk for attention and behavior disorders (ABD)?

The sample population consisted of 91 students from six second-grade classrooms who met the selection criteria. The $S S Q-R$, a rating scale designed for teachers to rate behavior related to attention and concentration, was used by classroom teachers to evaluate the subjects to determine if they were at risk for attention and behavior disorders. These results were tabulated along with the number of children diagnosed with speech and/or language disorders in 
this population.

Chi Square analysis showed no significant association for the two measures. It was found that of the 11 SLD subjects, 3 of them, or $27 \%$, were also ABD. Only 3 of the 17 ABD subjects (18\%) were also SLD. The 18\% of SLD subjects in the $A B D$ population and the $27 \%$ of $A B D$ subjects in the SLD group represent a higher percentage of $A B D$ and SLD than is expected in the general population. The higher than average incidence of SLD in the $A B D$ population warrants an awareness of this relationship and the realization that this will impact service delivery.

The results of this study indicate that the SSQ-R is not an appropriate measure for teachers to use in determining which children in their classroom would benefit from an assessment for speech and/or language disorders. The high number $(82 \%)$ of children identified by the SSQ-R as $A B D$ who were not SLD would identify many children who did not require speech and language evaluation. Conversely, the high number $(73 \%)$ of children not identified as ABD who were SLD by the SSQ-R would neglect many children who require speech/language intervention.

The results of this study are not to discount previous research that has suggested an association between attention deficit hyperactivity disorder, and speech and language disorders. It is likely that an association exists, but the 
present study was not able to demonstrate a significant correlation. 
CORRELATIONS BETWEEN THE SCHOOL SITUATIONS QUESTIONNAIREREVISED AND SPEECH AND LANGUAGE DISORDERS

by

GERALDINE TERESA COMERFORD

A thesis submitted in partial fulfillment of the requirements for the degree of

MASTER OF SCIENCE

in

SPEECH COMMUNICATION :

SPEECH AND HEARING SCIENCES

Portland State University

1993 
TO THE OFFICE OF GRADUATE STUDIES:

The members of the committee approve the thesis of Geraldine Teresa Comerford presented June 25, 1993.

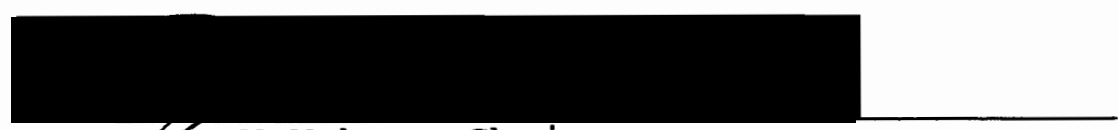

J Gan McMahon, Chair



Mary Gordpn-Brannan



Sheldon Maron

\section{APPROVED:}
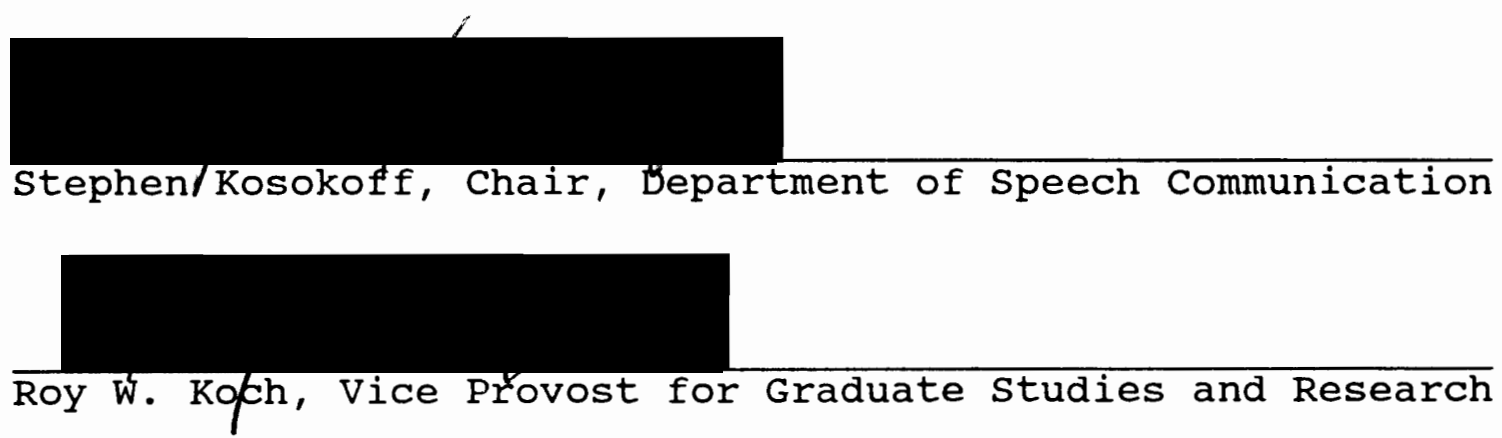


\section{ACKNOWLEDGEMENTS}

There are a great number of individuals who helped make the completion of my graduate studies possible. I am grateful to my family, friends, fellow students, supervisors, and professors who shared their knowledge, provided support, believed in me when I struggled, and assured me that someday I would graduate and become a speech-language pathologist.

I would like to especially thank my committee members; Joan McMahon, my thesis advisor, for her eagle eye and unending patience for many revisions, Mary Gordon-Brannon for her advice and wisdom, and sheldon Maron for his thoughtful input to this endeavor. A special thanks goes to Jack Hegrenes who brought statistics to life, and to John Coverstone who patiently helped me graph them out. I am also grateful to those individuals at Eccles Elementary School in Canby who provided the raw data for this research; LouAnn McCoy, Doris Robertson, Mary Christy, Cindy Coffaro, Jan McLeod, Charlie Schmiel, and Ellen Starr.

A special thank-you to my husband Gary for his endless patience, daily support of this project, and unshakable faith in my efforts. 
TABLE OF CONTENTS

PAGE

ACKNOWLEDGEMENTS . . . . . . . . . . . . . . . . . iii

LIST OF TABLES . . . . . . . . . . . . . . . . . vi

LIST OF FIGURES . . . . . . . . . . . . . . . . . vii

CHAPTER

I INTRODUCTION AND STATEMENT OF PURPOSE • • • . I Introduction . . . . . . . . . . . 1

Statement of Purpose . . . . . . 3

Terminology . . . . . . . . . 4

II REVIEW OF THE LITERATURE . . . . . . . . 6

Relationship of Behavior and Speech-

Language Disorders . . . . . 6

Behavioral Rating Scale...... 10

Speech and Language Evaluation . . . 11

III METHODS AND PROCEDURES . . . . . . . . 12

Subjects . . . . . . . . . 12

Instrumentation . . . . . . . . .12

Procedures . . . . . . . . . . 14

Subject Procurement

Speech and Language Evaluation

Testing Environment

School Situations QuestionnaireRevised (SSQ-R)

Administration 
Scoring Procedures and Data Analysis . 15

School Situations QuestionnaireRevised (SSQ-R) Scoring Procedures

Data Analysis RESULTS AND DISCUSSION • • • • • • • • • 18

Results . . . . . . . . . . . . 18

Primary Question

Descriptive Question 1

Descriptive Question 2

Descriptive Question 3

Descriptive Question 4

Discussion . . . . . . . . . . 21

V

SUMMARY AND IMPLICATIONS . . . . . . . . 26

Summary . . . . . . . . . . . 26

Implications . . . . . . . . . 28

Clinical

Research

REFERENCES

APPENDICES

A CONSENT FORMS . . . . . . . . . . . . . 33

B SCHOOL SITUATIONS QUESTIONNAIRE-REVISED • • . 34 


\section{LIST OF TABLES}

TABLE

PAGE

I Results of Chi Square Analysis of $\mathrm{ABD}$ and SLD Correlations . . . . . . . . 19 


\section{LIST OF FIGURES}

FIGURE

PAGE

1. Number and Distribution of SLD, $A B D$ and Normal Subjects . . . . . . . . 20

2. Number and Percentages of Subjects in $A B D$ and SLD Groups . • • • • • • • • • • 21 
CHAPTER I

INTRODUCTION AND STATEMENT OF PURPOSE

\section{INTRODUCTION}

Many children with emotional and/or behavioral disorders also present with speech and language disorders (Baker \& Cantwell, 1982; Prizant, Audet, Burke, Hummel, Maher, \& Theadore, 1990). Children with attention deficits, in particular, have shown a much higher incidence of speech and language disorders than does the general population (Camarata, Hughes, \& Ruhl, 1988; Cantwell \& Baker, 1987). A lack of awareness of the interaction of attention deficits and speech and language development by educators and speechlanguage pathologists may contribute to inadequate services for these children. Camarata et al. (1988) found that of the behaviorally disordered children with concomitant language disorders in their study, only $6 \%$ had been seen for speech and language services. Awareness of the relationship between speech and language impairments and psychiatric disorders is important for diagnosis and treatment of this population (Baker \& Cantwell, 1982; Prizant et al., 1990). Identification of school aged children who are speech and language impaired is a federally mandated requirement (Neidecker, 1987). Traditionally, the school speech- 
language pathologist has been responsible for conducting mass screenings to determine which children should be further evaluated for speech and language disorders. An effort to economize is one of the many reasons an increasing number of school districts are relying on teacher referrals to determine which children require speech-language evaluations. Unfortunately, teachers are frequently inaccurate in their referrals (James \& Cooper, 1966; Neidecker, 1987; Prahl \& Cooper, 1964). Although programs to train teachers in speech-language referrals have improved accuracy, the results are still poor (Neidecker, 1987). Evaluating children with attention deficits may also serve to identify students who are at risk for speech and language disorders. Providing teachers with an accurate and quick method for referrals would be highly beneficial for both the speech-language pathologist and teacher. The School Situations Questionnaire-Revised (Barkley, 1991) is the revised edition of The School Situations Questionnaire, a valid and reliable screening device (Altepeter \& Breen, 1989, Breen \& Altepeter, 1991). It was designed for teachers to rate behavior related to attention and concentration. This instrument may serve as a useful tool for identifying students with attention deficits and children whose speech and language should also be assessed. 
STATEMENT OF PURPOSE

The purpose of this study was to determine the effectiveness of the school situations Questionnaire-Revised (SSQ-R) (Barkley, 1991) in identifying 91 children in the second grade, aged 7:0 to 8:11, who are speech and/or language disordered. This study sought to answer the following primary question:

Is there an association between the diagnosis of speech and/or language disorders, and detection by the SSQ-R as at risk for attention and behavior disorders?

The following secondary questions serve as descriptive information of the data gathered and provide additional information and insight into the sample studied:

1. What is the percentage of children at risk for attention and behavior disorders who were also diagnosed as speech and/or language disordered?

2. What is the percentage of children who were not detected by the SSQ-R as at risk for attention and behavior disorders, and who also were not diagnosed as speech and/or language disordered?

3. What is the percentage of false positives produced by the SSQ-R, that is, the number of children detected by the SSQ-R as at risk for attention and behavior disorders, but who were not diagnosed as speech and/or language disordered?

4. What is the percentage of false negatives produced 
by the SSQ-R, that is, the number of children not detected as at risk for attention and behavior disorders, but who were diagnosed as speech and/or language impaired?

\section{TERMINOLOGY}

The following list of definitions will aid in clarifying terms used in this paper:

1. At Risk For Attention and Behavior Disorders (ABD): For the purposes of this study children whose scores are greater than 1.5 standard deviations above the mean for their age and sex on the SSQ-R will be defined as at risk for attention disorders.

2. Attention: "The ability to focus in a sustained manner on one activity. A disturbance in attention may be manifested by difficulty in finishing tasks that have been started, easy distractibility, or difficulty in concentrating on work" (American Psychiatric Association, 1987, p. 392).

3. Attention Deficit Disorder (ADD): Developmentally inappropriate inattention and impulsivity (American Psychiatric Association, 1980).

4. Attention Deficit Hyperactivity Disorder (ADHD): The essential features of ADHD are "developmentally inappropriate degrees of inattention, impulsiveness and hyperactivity" (American Psychiatric Association, 1987, p. $50)$. 
5. Behaviorally Disordered (BD): The term Behaviorally Disordered (BD) has been adopted by many states and used by education professionals to describe a population of children with emotional and/or behavioral disorders (Camarata et al., 1988).

6. Hyperactive: "A qualitative and quantitative description of motoric behavior or motility, a nonspecific symptom of a variety of medical and behavioral disorders, and a common syndrome of childhood psychopathology first identified over a hundred years ago" (Corsini \& Ozaki, 1984, p. 170)

7. Minimal Brain Dysfunction: Minimal Brain Dysfunction (MBD) was introduced by clement and Peters (1962) to reflect the subtle neurological deviations often noted in children with behavior and learning disorders.

8. Speech and Language Disordered (SLD): Those students who were identified by the school speech-language pathologist, with standardized speech and/or language tests, as having a speech and/or language delay or disorder severe enough to warrant intervention. 
CHAPTER II

REVIEW OF THE LITERATURE

RELATIONSHIP OF BEHAVIOR AND SPEECH-LANGUAGE DISORDERS

There is speculation, but no generally accepted theory, for the causes of ADHD or the nature of its relationship to speech and language disorders. It would seem logical to conclude that children who have difficulty regulating attention span may lack the skills to attend to, and learn, language. The reverse also seems logical, that their difficulties with speech and language are at the root of their attention deficit (Cantwell \& Baker, 1991). The underlying causes are unknown; however, numerous researchers have concluded that this population is at risk for speech and language disorders (Baltaxe \& Simmons, 1988; Cantwell \& Baker, 1987; Prizant et al., 1990).

The disorders of ADD with Hyperactivity and ADD without Hyperactivity were defined by the American Psychiatric Association in the third edition of the Diagnostic and Statistical Manual, (DSM III), in 1980. This publication of the definitions of ADD with and without hyperactivity helped to establish the legitimacy of these disorders and emphasized attention over activity as the cardinal sign of the disorder (Epstein, Shaywitz, Shaywitz, \& Woolston, 
1991). The features of the two were essentially the same, with the exception of hyperactivity in the second group. The definitions of these disorders were updated and consolidated into one disorder of Attention-deficit Hyperactivity Disorder (ADHD) in the 1987 DSM III-R.

Children with attention disorders, such as ADD or ADHD, (and other related disorders) have higher than average rates of speech and language disorders (Cantwell \& Baker, 1991; Prizant et al., 1990). In one of the largest studies, Cantwell and Baker (1987) studied 600 children (mean age of 5:7) who were referred to a speech and hearing clinic in Los Angeles. Psychiatric evaluations were conducted and the following diagnoses appeared: Overt Behavior Disorders (including ADD, Conduct Disorder, and oppositional Disorder), Emotional Disorders, and others. The children were also separated into three groups based on their speech and language skills. These groups were speech disorders, combined speech and language disorders, and language disorders. Behavioral disorders were discovered in $30 \%$ of those in the speech and language group, $14 \%$ in the speech only group, and $47 \%$ in the language disordered only group. other researchers have also noted a higher prevalence for speech and language disorders in the behavioral or attention disordered population. Love \& Thompson (1988) examined the diagnoses of 116 children referred for outpatient psychiatric care. They found the overall prevalence for 
dual diagnosis of language disorders and ADD (48.3\%) to be almost triple the rate for language disorder alone (16.4\%) and double the rate for attention deficit disorder alone (25\%). Prizant et al. (1990) found that $67 \%$ of admissions to a children's inpatient psychiatric unit failed a speech and language screening, a much higher prevalence than the estimated 8 to $10 \%$ found in the general population (Phillips, 1975 as cited in Neidecker, 1987). Hartsough \& Lambert (1985) analyzed medical factors differentiating hyperactives from control groups and found speech problems were reported more frequently (27\%) than for controls (15\%). Paul \& James (1990) found that significantly greater differences existed for activity/attention, conduct, and mood as reported by parents of toddlers with slow language acquisition as compared to toddlers with normal speech and language development. They concluded that parents perceive toddlers with slow expressive language acquisition to show the greatest difference in regulating activity and attention, as well as differing from normals in conduct and mood. In another study in Los Angeles, 125 children referred and diagnosed with speech and language disorders were found to have a $20 \%$ incidence of behavioral disorders (Baltaxe \& Simmons, 1988). Prizant et al. (1990) concluded that there is evidence of a relationship between communication disorders and emotional/behavioral disorders. Many of the previously mentioned studies have 
identified moderate to severe levels of psychiatric disorders. These children are often served in special schools. Camarata et al. (1988) noted that many students with milder emotional/behavioral difficulties are mainstreamed in public schools. In their 1988 study, Camarata et al. tested all children in a school district who met criteria for being mild to moderately behavioral disordered (BD). Thirty-eight children aged 8:9 to $12: 11$ were administered The Test of Language DevelopmentIntermediate (TOLD-I) (Hammill \& Newcomer, 1982). The TOLD-I consists of five subtests and provides normative data. Twenty-seven, or $71 \%$ of the total sample, performed two or more standard deviations below the normative sample, on one or more of the subtests. Ten of the remaining 11 students received standard scores one standard deviation below the mean on one or more of the subtests. Only one child of the 38 tested, performed at an average level for all subtests demonstrating the high prevalence of speech and language disorders in this population. Camarata et al. (1988) concluded that the pattern of below-normal performance was consistent for all BD children and indicated that this is a population at risk for potential language problems. A review of case files for each of the children indicated that only $6 \%$ ( 2 of the 38 ) had been seen for speech-language services, indicating that these children are not being identified for speech-language services. 
BEHAVIORAL RATING SCALE

The previous literature review suggests that identification of behavioral or attention disordered children may also detect children at risk for speech and language disorders. Teacher rating scales do not yield a diagnosis, but are valuable and provide well-organized descriptions of behavior (Breen \& Altepeter, 1991; Friedman \& Doyall, 1987). A rating scale is frequently employed to identify children as hyperactive or at risk for attention disorders (Zentall \& Barack 1979). Teachers' ratings of behavior tend to be more reliable and sensitive to hyperactive behaviors than that of parents (Barkley, 1981; Guevremont, DuPaul, \& Barkley, 1990). The school environment provides the classroom teacher with the unique opportunity of observing a child in a variety of academic and social tasks. Teachers' frequent contact with a large number of children provide age and sex appropriate standards, and allow them to be relatively objective (Atkins \& Pelham, 1991). Teachers can reliably screen for children who are at risk for attention and behavioral disorders using the SSQ-R (Barkley, 1991).

The SSQ-R (Barkley, 1991) was chosen for this study to identify children who are at risk for attention and behavioral disorders in the classroom. This scale lists eight school situations and the teacher is asked to indicate whether or not the child has difficulty paying attention or 
concentrating in each situation. The situations are individual deskwork, small group activities, free-play time in class, lectures in class, field trips, assemblies, movies, and class discussions. The teacher then rates the problem areas from mild (1) to severe (9). Two scores are derived, the number of problem settings and the mean problems settings score. These scores can then be compared to established norms (Barkley, 1991).

\section{SPEECH AND LANGUAGE EVALUATION}

The Joliet 3-Minute Speech and Language Screening (Kinzler \& Johnson, 1983) was used in this study to screen subjects for speech and/or language disorders. The Joliet is a standardized screening device that examines a child's speech and language production by identifying pictures and repetition of sentences. Other standardized tests of speech and language ability which are used to determine eligibility for intervention from the speech-language pathologist may include, but are not limited to, The Test of Language Development-Primary (TOLD-P) (Newcomer \& Hammill, 1982), Test of Auditory Perceptual Skills (TAPS) (Gardner, 1985), The structured Photographic Articulation Test (SPAT) test of articulation (Kresheck \& Werner, 1989), and a language sample. 
CHAPTER III

\section{METHODS AND PROCEDURES}

The following will present the methods utilized in this study. Subject selection, the environment, procedures, instrumentation, and data analysis will be presented.

\section{SUBJECTS}

The subjects for this study were recruited from the second grade population in Canby Public Schools (State of Oregon). The sample population consisted of 91 students from six classrooms at Eccles Elementary School who met the selection criteria. Selection criteria were as follows: all male and female students in the regular education second grade classrooms ranging in age from $7: 0$ to $8: 11$ whose parents returned permission slips (see Appendix A). Children with hearing impairments or those receiving speech and language services were not excluded. Children with physical disabilities were not included in the study.

\section{INSTRUMENTATION}

The School Situations Questionnaire-Revised (SSQ-R) (Barkley, 1991) is a recently developed questionnaire to evaluate behavior and attention in selected school 
situations (see Appendix B). The original School Situations Questionnaire demonstrates sound psychometric properties (Guevremont et al., 1990) with preliminary results indicating acceptable levels of test re-test reliability and discrimination between children with and without ADHD (Atkins \& Pelham, 1991; Barkley, 1991). The revised version, SSQ-R, was created to permit evaluation of problems children may have with attention and concentration in specific situations. This instrument was chosen over other teacher rating scales because of its checklist format, allowing busy teachers to complete it in a timely fashion. The SSQ-R was also chosen for its normative data and emphasis on attention and concentration deficits (Barkley, 1991).

The classroom teacher is required to indicate whether or not a child is a problem in each of 8 areas, if so then a severity rating of 1 to 9 ( 9 being the most severe) is assigned to that area. Two scores are derived, the number of problem settings and their mean severity rating. Results are clinically significant if a child scores 1.5 standard deviations above the mean (93rd percentile) on either score. standardized norms are provided for boys and girls 6 to 12 years of age (Barkley, 1991). 
PROCEDURES

\section{Subject Procurement}

Parent consent forms (see Appendix A), explaining the purpose of the study, were sent home with each student. After one week 68 consent forms were returned. A second letter and consent form was sent home with students who had not returned the initial consent forms. 23 additional consent forms were returned for a total of 91; these students were enrolled in the study.

\section{Speech and Language Evaluation}

The second grade students at Eccles Elementary School were screened for speech and or language problems in the fall of 1992. The Joliet 3-Minute Speech and Language Screening was used for this purpose by the school speechlanguage pathologist. Children failing this screening were further evaluated with standardized testing conducted by the school speech-language pathologist. Results of the standardized testing determined which children were speech and/or language disordered (SLD) to such a degree as to require intervention. class rosters listing the students' names were obtained from the school speech-language pathologist. The list of eligible subjects was reviewed by the examiner and school speech-language pathologist; those children who were speech and/or language disordered were noted on the class roster. 
Testing Environment

All students were evaluated at the same school. Each classroom was approximately the same size and contained similar furnishings.

\section{School Situations Questionnaire-Revised (SSO-R)} Administration

The six classroom teachers of the subjects were interviewed in their classrooms after students had left at the end of the school day. The procedures for filling out the SSQ-R were explained by the investigator, and a copy of the questionnaire for each eligible student was provided. The name, age, and sex of subjects were noted by the investigator according to information provided on the parent consent forms. Teachers were instructed to observe the subjects' behavior and to complete the rating scale during appropriate and available classroom activities. The completed questionnaires were retrieved from the teachers approximately 2 weeks later.

In order to preserve each student's confidentiality, the examiner, after noting on the completed SSQ-R forms whether or not the student was SLD, blackened out the names and assigned each subject a test number.

$$
\text { SCORING PROCEDURES AND DATA ANALYSIS }
$$

School Situations Questionnaire-Revised (SSQ-R) Scoring Procedures

The SSQ-R questionnaires were scored according to 
instructions in the test manual (See Appendix B). For each questionnaire, the number of problem situations was calculated as well as the mean severity rating for all situations. Established norms and standard deviations are provided in the test manual; cutoff scores 1.5 standard deviations above the norm were calculated according the directions in the manual. Females age 7 who had either 7 or more problem situations or had a mean severity rating of 6.37 or greater, and females age 8 who had either 6 or more problem situations or had a mean severity rating of 5.06 or greater were 1.5 standard deviations above standardized norms, and thus were considered at risk for attention and behavior deficits (ABD). Males age 7 who had 8 problem situations or with a mean severity rating of 6.85 or greater, and males age 8 who had 7 or more problem situations or with a mean severity rating of 5.26 or greater were 1.5 standard deviations above standardized norms and similarly were considered ABD.

\section{Data Analysis}

Descriptive analysis consisted of assigning individual subjects to one of four groups and determining the number and percentages of subjects in each group. Group one consisted of those who were judged ABD by the SSQ-R and who were also SLD. Group two consisted of those who were judged $A B D$ by the SSQ-R, but were not SLD. Group three consisted of those subjects judged not to be ABD by the SSQ-R, but who 
were SLD. The fourth group consisted of those subjects who were neither $A B D$ nor SLD. A $2 \times 2$ contingency table was used to display the four groups. A Chi Square analysis was utilized to answer the primary question: is there an association between the diagnosis of speech and/or language disorders, and detection by the SSQ-R as at risk for attention and behavior disorders? In order to state the predicted result that $S L D$ and $A B D$ are correlated, Chi square must be greater than the critical value at a .05 level. 
CHAPTER IV

RESULTS AND DISCUSSION

RESULTS

The purpose of this study was to determine the effectiveness of the SSQ-R in identifying children who are SLD in a public school second grade population. The subjects were assigned to one of four groups according to their performance on the SSQ-R and their diagnosis as SLD or not SLD. Group 1 consists of subjects SLD and ABD $(n=3)$, group 2 consists of subjects ABD and not SLD $(n=14)$, group 3 consists of subjects SLD and not $\operatorname{ABD}(n=8)$, group 4 consists of subjects neither ABD nor SLD $(n=66)$. The number of subjects for each group was then placed in a $2 \times 2$ contingency table in order to perform a chi square analysis and answer the primary question. Descriptive analysis was then employed to answer the four descriptive questions.

\section{Primary Question}

The recommended minimum for each cell in a Chi square analysis is five (Witte, 1989). Although one cell did not meet the recommended criteria, it was judged that a Chi Square analysis may provide some information to help answer the primary question: is there an association between SLD 
and $A B D$ subjects? The obtained Chi square of .61 was not large enough to obtain significance. See Table I.

TABLE I

RESULTS OF CHI SQUARE ANALYSIS OF ABD AND SLD CORRELATIONS

\begin{tabular}{||l|c|c|c|}
\hline & ABD & Not ABD & Totals \\
\hline SLD & $\begin{array}{c}\mathrm{n}=3 \\
\star(2.05)\end{array}$ & $\begin{array}{c}\mathrm{n}=8 \\
*(8.95)\end{array}$ & $\mathrm{n}=11$ \\
\hline Not SLD & $\begin{array}{c}\mathrm{n}=14 \\
\star(14.95)\end{array}$ & $\begin{array}{c}\mathrm{n}=66 \\
\star(65.05)\end{array}$ & $\mathrm{n}=80$ \\
\hline & $\mathrm{n}=17$ & $\mathrm{n}=74$ & $\mathrm{~N}=91$ \\
\hline
\end{tabular}

*Expected Frequencies

Degrees of Freedom $=1$, Chi square to be significant at .05 must $=3.84$. Obtained $\mathrm{Chi}$ square $=.61$, not significant.

Although the results of Chi square analysis are compromised by the low number of subjects in cell 1 , it would appear that the low number of subjects with both ABD and SLD would confirm the result that there is no significant relationship between the two disorders.

Descriptive Question 1

What is the percentage of children who were detected by the SSQ-R as ABD who were also diagnosed as SLD? Twentyseven percent of the SLD subjects, 3 out of 11 , were detected as ABD by the SSQ-R. See Figures 1 and 2 . 


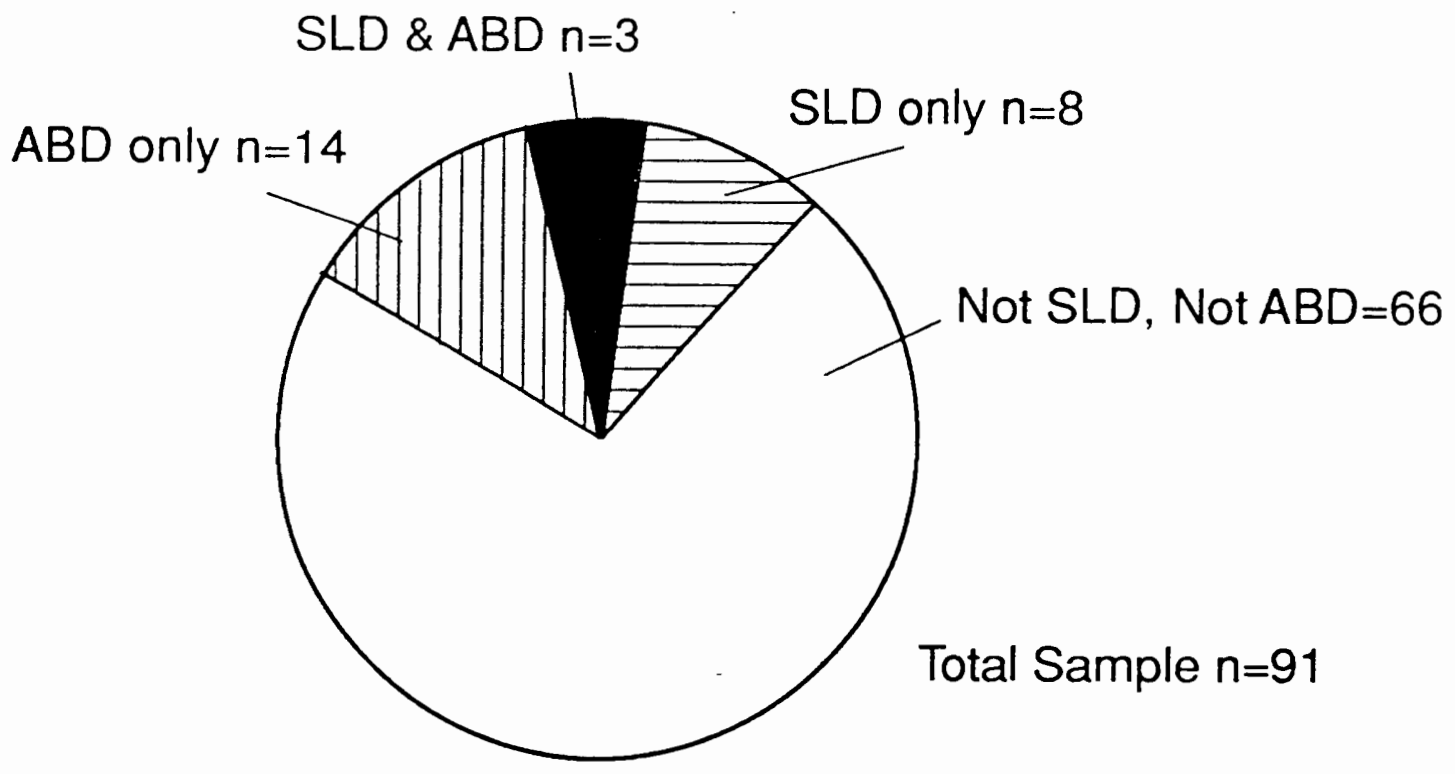

Figure 1. Number and distribution of SLD, ABD and normal subjects.

\section{Descriptive Question 2}

What is the percentage of children who were not detected by the SSQ-R as $A B D$, and who also were not diagnosed as SLD? Seventy-three percent of the total sample, 66 out of 91 subjects were neither ABD or SLD. See Figure 2.

\section{Descriptive Question 3}

What is the percentage of false positives, those children identified as at risk for $A B D$ by the SSQ-R, but who were not diagnosed as SLD? Eighty-two percent, 14 of the 17 subjects detected by the SSQ-R as ABD were not SLD. See. Figures and 2 . 
Descriptive Question 4

What is the percentage of false negatives, those children not identified as at risk for ABD by the SSQ-R, but who were diagnosed as SLD? Seventy-three percent, 8 of the 11 SLD subjects were not identified as ABD by the SSQ-R. See Figures 1 and 2 .

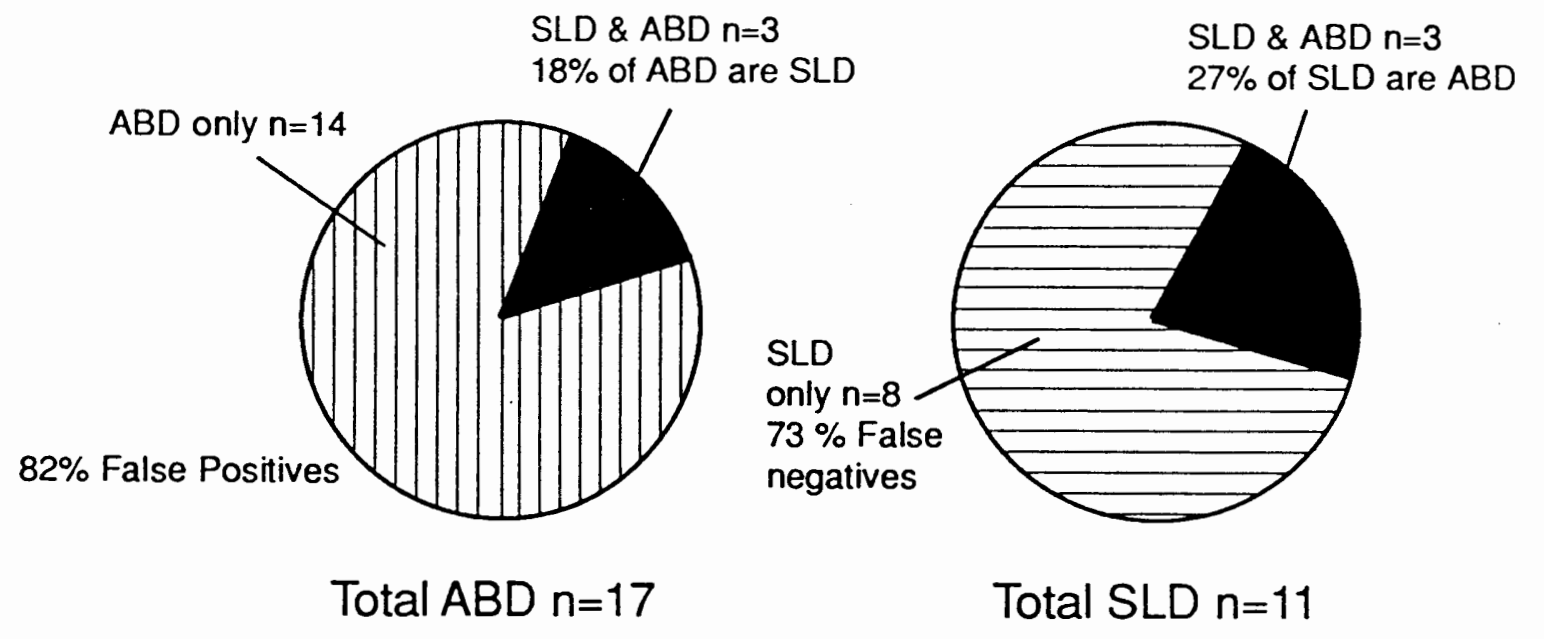

Figure 2. Number and percentages of subjects in and $\mathrm{ABD}$ and SLD groups.

\section{DISCUSSION}

The purpose of this study was to determine if the SSQ-R could be used by classroom teachers to screen for speech and language disorders. The results of this study demonstrate no significant correlation between the SSQ-R and speech and/or language disorders, and indicate the SSQ-R would not be useful for this purpose. The high percentage ( $82 \%$ ) of false positives would identify many children who were ABD but not SLD, and the high percentage of false negatives 
(73\%) would result in non-identification of many SLD children, and be a further contraindication for using the SSQ-R for this purpose.

This research was based upon the premise that numerous researchers are concerned that the ADHD population is at risk for speech and language disorders (Baltaxe \& Simmons, 1988; Cantwell \& Baker, 1987; Prizant et al., 1990). Previous researchers have reported a higher incidence of speech and language disorders in the ADHD population (Camarata et al., 1988; Cantwell \& Baker, 1987). Although this study did not presume to identify children who are ADHD, the instrument used to determine at risk for attention and behavior disorders $(A B D)$ has been shown to differentiate ADHD from non-ADHD children (Guevremont et al., 1989).

The number of ABD subjects for this study was 17 (19\%) of the total population sampled, higher than the expected 3$5 \%$ in the general population (American Psychiatric Association, 1987; Barkley, 1991; CHADD, 1991). The higher than expected percentage of $A B D$ subjects in the population sampled could be the result of a variety of factors, including inadequate training on the $S S Q-R$ resulting in improper administration, or a higher than average prevalence of children with attention and concentration difficulties. Another factor to consider is that this is only one instrument for rating concentration and attention. In order to make a diagnosis of ADHD, symptoms must be observed for a 
period of 6 months or more (American Psychiatric Association, 1987), and parent and child interviews are necessary (Barkley, 1987). It is likely that a more complete evaluation of these children would have resulted in a smaller number of behavior disorders to correlate with SLD.

Eleven of the 91 subjects (12\%) in the population sampled in this study were discovered to be speech and/or language disordered. This is slightly higher than the expected $8-10 \%$ found in the general population and may reflect a minor variation in the population sampled.

It is important to note that 3 of the 11 (27\%) of the SLD subjects in this study were found to be $A B D$, higher than the expected $3-4 \%$ of the general population. This could result from the higher than expected number of $A B D$ subjects found in this sample, or could indicate that the SLD population may have a higher incidence of $\mathrm{ABD}$. The $27 \%$ incidence of SLD in the ABD population is consistent with the 1987 Baker and Cantwell study of 600 children in which they found $30 \%$ of their speech and language disordered subjects to have a behavior disorder. Results from the present study are slightly higher than the 1988 Baltaxe \& Simmons study in Los Angeles, in which $20 \%$ of children referred and diagnosed with speech and language disorders were found to have behavioral disorders. The results of this study in which 3 of the $17 \mathrm{ABD}$ 
subjects (18\%) were found to be SLD, are in contrast to the 1988 study by Camarata et al. in which they found a higher incidence of language disorders in a behavioral disordered population. They tested all children in a school district who met criteria for being mild to moderately behavioral disordered (BD). Thirty-eight children aged 8:9 to $12: 11$ were administered The Test of Language DevelopmentIntermediate (TOLD-I) (Hammill \& Newcomer, 1982). Twentyseven (71\%) of their total sample performed two or more standard deviations below the norm on one or more of the subtests. It may be that the lower incidence (18\%) of SLD in this study results from comparing children who have been termed at risk from one teacher rating, versus children who are mild to moderately behavior disordered and may represent a more severely disordered population. Another variable between the two studies is the higher age in the camarata et al. (1988) sample.

The results of this study do not suggest that identifying children who are at risk for attention and behavior disorders is an effective means of identifying children who should be assessed for speech and language disorders. Although there was not a significant correlation between the populations, it does appear that the behaviorally disordered population is at risk for speech and/or language disorders. Speech-language pathologists must be aware and sensitive to the possibility that their 
clients may have concomitant attention and behavior disorders. It is also important that speech-language pathologists share this information with other members of the educational team, so that a language disorder does not go unnoticed in a child who is experiencing attention and/or behavior disorders. 


\author{
CHAPTER V \\ SUMMARY AND IMPLICATIONS
}

SUMMARY

Many children with emotional and/or behavioral disorders also present with speech and language disorders (Baker \& Cantwell, 1982; Prizant et al., 1990). Children with attention deficits, in particular, have shown a much higher incidence of speech and language disorders than does the general population (Camarata et al., 1988; Cantwell \& Baker, 1987).

Traditionally, school speech-language pathologists have been responsible for conducting mass screenings to determine which children should be further evaluated for speech and language disorders. An increasing number of school districts are relying on teacher referrals to determine which children require speech-language evaluations. It was hypothesized that if teachers were able to identify children with attention deficits, these children may be appropriate for referral to speech-language pathologists for speech and language evaluation.

The purpose of this study was to determine the effectiveness of the School Situations Questionnaire-Revised (SSQ-R) (Barkley, 1991) in identifying children in the 
second grade, aged 7:0 to $8: 11$, who are speech and/or language disordered. This study sought to answer the following primary question: is there an association between the diagnosis of speech and/or language disorders (SLD), and detection by the SSQ-R as at risk for attention and behavior disorders $(A B D)$ ?

The sample population consisted of 91 students from six second-grade classrooms who met the selection criteria. The SSQ-R, a rating scale designed for teachers to rate behavior related to attention and concentration, was used by classroom teachers to evaluate the subjects to determine if they were at risk for attention and behavior disorders. These results were tabulated along with the number of children diagnosed with speech and/or language disorders in this population.

Chi Square analysis showed no significant association for the two measures. It was found that of the 11 SLD subjects, 3 of them, or 27\%, were also $A B D$. Only 3 of the 17 ABD subjects (18\%) were also SLD. The $18 \%$ of SLD subjects in the $A B D$ population and the $27 \%$ of $A B D$ subjects in the SLD group represent a higher percentage of $A B D$ and SLD than is expected in the general population. The higher than average incidence of SLD in the ABD population warrants an awareness of this relationship and the realization that this will impact service delivery. 


\section{IMPLICATIONS}

\section{clinical}

The results of this study indicate that the $S S Q-R$ is not an appropriate measure for teachers to use in determining which children in their classroom would benefit from an assessment for speech and/or language disorders. It is difficult to hypothesize if the use of other behavior rating scales would have similar results. Perhaps a scale that identified a smaller number of behaviorally disordered students would result in fewer false positives, and serve as an indicator for children who would benefit from speech and language screening.

The higher than average incidence of SLD in the ABD population warrants an awareness of this relationship and the realization that this will impact service delivery. The speech-language pathologist may be the first person to realize that more than just speech and/or language disabilities are present. In this instance the responsibility for alerting the parents and proper specialists within the school district rests with the speech-language pathologist.

\section{$\underline{\text { Research }}$}

The results of this study are not to discount previous research that has suggested an association between attention 
deficit hyperactivity disorder, and speech and language disorders. It is possible that an association exists, but the present study was not able to demonstrate a significant correlation. The small percentage of $A B D$ and SLD children in the general population require a large initial population in order to generate sufficient subjects. Future research in this area would benefit from a sample of at least 180 subjects in order to have large enough numbers to analyze statistically.

Results of this study may have also been influenced by a limited cultural population that consisted of mainly white and some hispanic children. It would be interesting to discover if similar results would occur in a more culturally diverse population. Further research would also benefit from a collaborative effort of speech-language pathologists and child behavior specialists in order to make a more definitive diagnosis of a behavior disorder. 
REFERENCES

Altepeter, T. S., \& Breen, M. J. (1989). The home situations questionnaire (HSQ) and the school situations questionnaire (SSQ): normative data and an evaluation of psychometric properties. Journal of Psychoeducational Assessment, $7,312-322$.

American Psychiatric Association: Diagnostic and statistical manual of mental disorders (3rd ed.). Washington, DC, American Psychiatric Association, 1980.

American Psychiatric Association: Diagnostic and statistical manual of mental disorders (3rd ed., revised). Washington, DC, American Psychiatric Association, 1987.

Atkins, M. S., \& Pelham, W. E. (1991). School-based assessment of attention deficit-hyperactivity disorder. Journal of Learning Disabilities 24, (4) 197-204.

Baker, L., \& Cantwell, D. P. (1982). Psychiatric disorder in children with different types of communication disorders. Journal of Communication Disorders 24 , 113-126.

Baker, L., \& Cantwell, D. P. (1987). A prospective psychiatric follow-up of children with speech/language disorders. Journal of the American Academy of Child Psychiatry 26, (4) 546-553.

Baltaxe, C. A., \& Simmons J. Q. (1988). Communication deficits in preschool children with psychiatric disorders. Seminars in speech and Language 9, 81-91.

Barkley, R. A. (1981). Hyperactive children: Handbook for diagnosis and treatment. New York, Guilford Press.

Barkley, R. A. (1987). The assessment of attention deficithyperactivity disorder. Behavioral Assessment 9, 207233.

Barkley, R. A. (1991). Attention-deficit hyperactivity disorder: A clinical workbook. New York, Guilford Publications, Inc. 
Breen, J. M. \& Altepeter, T. S. (1991). Factor structures of the home situations questionnaire and the school situations questionnaire. Journal of Pediatric Psychology 16, 59-67.

Camarata, S. M., Hughes, C. A., \& Ruhl, K. L. (1988). Mild/moderate behaviorally disordered students: a population at risk for language disorders. Language, speech, and Hearing Services in Schools, 19, 191-200.

Cantwell, D. P., \& Baker, L. (1987). Prevalence and type of psychiatric disorder and developmental disorders in three speech and language groups. Journal of communication Disorders, 20, 151-160.

Cantwell, D. P., \& Baker, L. (1991). Association between attention deficit-hyperactivity disorder and learning disorders. Journal of Learning Disabilities, 24 , 88-95.

Children With Attention Deficit Disorders (CH.A.D.D.) (1991). Attention deficit disorders: A Guide for teachers. Portland, Oregon: Education Committee of CH.A.D.D.

Clement, S. D., \& Peters, (1962). Brain dysfunction-school aged child. Archives of General Psychiatry, 6 , 185197 .

Corsini, R. J., \& Ozaki, B. D. (Eds.). (1984). Encyclopedia of psychology vol. 2. New York: John Wiley \& Sons.

Epstein, M. A., Shaywitz, S. E., Shaywitz, B. A., \& Woolston, J. L, (1991). The boundaries of attention deficit disorder. Journal of Learning Disabilities, 24, (2) 78-86.

Friedman, \& Doyall, (1987). Attention deficit disorder and hyperactivity, 2nd ed. Austin: ProEd.

Gardner, M. F. (1985). Test of Auditory-Perceptual Skills (TAPS). Children's Hospital of San Francisco: Publication Department.

Guevremont, D. C., Dupaul, F. J., \& Barkley, R. A. (1990). Diagnosis and assessment of attention deficithyperactivity disorder in children. Journal of School Psychology, 28, 51-78.

Hammill, D. D., \& Newcomer, P. (1982). Test of Language Development-Intermediate (TOLD-I). Austin, Texas: ProEd. 
Hartsough, C. S., \& Lambert, N. M. (1985). Medical factors in hyperactive and normal children. American Journal of orthopsychiatry, 55, (2) 190-201.

James, H. P., \& Cooper, E. B. (1966). Accuracy of teacher referrals of speech handicapped children. Exceptional Children, 33, 29-33.

Kinzler, M. C., \& Johnson, C. C., (1983). Joliet 3-Minute Speech and Language Screen. Tucson, Arizona: Communication skill Builders.

Kresheck, J. D. , \& Werner, E. O. (1989) . Structured Photographic Articulation Test (SPAT). Sandwich, Illinois: Janelle Publications.

Love, A. J., \& Thompson, M. G. (1988). Language disorders and attention deficit disorders in young children referred for psychiatric services: analysis of prevalence and a conceptual synthesis. American Journal of orthopsychiatry, 58, (1) 52-64.

Neidecker, E. A. 1987. School programs in speech and language. Englewood Cliffs, New Jersey: Prentice-Hall, Inc.

Newcomer, P. L., \& Hammill, D. D., (1982). Test of Language Development-Primary (TOLD-P). Austin, Texas: ProEd.

Paul, R. \& James, D. (1990). Language delay and parental perceptions. Journal of the American Academy of Child and Adolescent, $\underline{29}$, 669-670.

Prahl, H. M., \& Cooper, E. B. (1964). Accuracy of teacher referrals of speech-handicapped school children. ASHA, 6, no. 10, Convention Abstracts, p. 32 .

Prizant, B. M., Audet, L. R., Burke, G. M. , Hummel, L. J., Maher, S. R., \& Theadore, G. (1990). Communication disorders and emotional/behavioral disorders in children and adolescents. Journal of Speech and Hearing Disorders, 55, 179-192.

Witte, R. S. 1989. Statistics 3rd ed. Orlando, Florida: Holt, Rinehart and Winston Inc.

Zentall, S. S., \& Barack, R. S. (1979). Rating scales for hyperactivity: concurrent validity, reliability, and decisions to label for the Conners and David's abbreviated scales. Journal of Abnormal Child Psychology, 7, (2) 179-190. 


\section{APPENDIX A}

\section{CONSENT FORM}

I agree to let my child

participate as a subject in the study titled "Correlations Between The school situations Questionnaire-Revised and speech and Language Disorders." This study will be conducted by Geraldine Comerford under the supervision of Joan McMahon, thesis director at the speech and Hearing Sciences Program, Portland State University.

In this study, my child's classroom teacher will complete the School situations Questionnaire-Revised to assess attention and concentration in different classroom situations. These results will be compared to the speech and language screenings completed at the beginning of the school year. There are no risks involved in this study. I am free to refuse to let my child participate or to withdraw him/her from the study without prejudice. In order to insure my child's anonymity, no names will be used when results are tabulated and presented. Instead, he or she will be assigned a number, which will be used for identification purposes. The study requires no additional time from my child. The purpose of this study is to determine the usefulness of the School situations Questionnaire-Revised in identifying children who are at risk for speech and language difficulties.

Please complete the bottom portion of this form and have your child return it to the classroom teacher by Friday, March 19, 1993. Please retain the top portion for your records. If you have any questions, please feel free to contact me at 769-6605. If your child experiences any problems that are the result of participation in this study, please contact the chair of the Human subjects Research and Review Committee, Office of Grants and Contracts, 105 Neuberger Hall, Portland State University, 503/725-3417.

\section{CONSENT FORM}

I agree to let my child participate as a subject in the study titled "Correlations Between The School Situations Questionnaire-Revised and Speech and Language Disorders." This study will be conducted by Geraldine Comerford under the supervision of Joan McMahon, thesis director at the speech and Hearing Sciences Program, Portland State University. 


\section{APPENDIX B}

\section{SCHOOL SITUATIONS QUESTIONNAIRE-REVISED}

\section{Name of Child}

Name of Person Completing This Form

Does this child have problems paying attention or concentrating in any of these situations? If so, indicate how severe these attentional difficulties are.

Situations

During individual deskwork

During small-group activities

During free-play time in class

During lectures to the class

On field trips

During special assemblies

During movies, filmstrips

During class discussions
Yes/No If yes, how severe?

(Circle one) Mild (Circle one) Severe

$\begin{array}{lllllllllll}\text { Yes } & \text { No } & 1 & 2 & 3 & 4 & 5 & 6 & 7 & 8 & 9 \\ \text { Yes } & \text { No } & 1 & 2 & 3 & 4 & 5 & 6 & 7 & 8 & 9 \\ \text { Yes } & \text { No } & 1 & 2 & 3 & 4 & 5 & 6 & 7 & 8 & 9 \\ \text { Yes } & \text { No } & 1 & 2 & 3 & 4 & 5 & 6 & 7 & 8 & 9 \\ \text { Yes } & \text { No } & 1 & 2 & 3 & 4 & 5 & 6 & 7 & 8 & 9 \\ \text { Yes } & \text { No } & 1 & 2 & 3 & 4 & 5 & 6 & 7 & 8 & 9 \\ \text { Yes } & \text { No } & 1 & 2 & 3 & 4 & 5 & 6 & 7 & 8 & 9 \\ \text { Yes } & \text { No } & 1 & 2 & 3 & 4 & 5 & 6 & 7 & 8 & 9\end{array}$

Office Use Only: No. problems Mean severity

Note. From The Home and School Situations Questionnaires-Revised: Normative Data, Reliability, and Validity by G. J. DuPaul, 1990, unpublished manuscript, University of Massachusetts Medical Center, Worcester. Reprinted by permission of the author. This form may be reproduced for personal use. 